University for Business and Technology in Kosovo

UBT Knowledge Center

UBT International Conference

2018 UBT International Conference

Oct 27th, 1:30 PM - 3:00 PM

\title{
Logistics Support Issues in Disaster Operations
}

\author{
Vedat Shaqiri \\ University of Hertfordshire, vs15aaa@herts.ac.uk
}

Follow this and additional works at: https://knowledgecenter.ubt-uni.net/conference

Part of the Business Commons

\section{Recommended Citation}

Shaqiri, Vedat, "Logistics Support Issues in Disaster Operations" (2018). UBT International Conference. 301.

https://knowledgecenter.ubt-uni.net/conference/2018/all-events/301

This Event is brought to you for free and open access by the Publication and Journals at UBT Knowledge Center. It has been accepted for inclusion in UBT International Conference by an authorized administrator of UBT Knowledge Center. For more information, please contact knowledge.center@ubt-uni.net. 


\title{
Logistics Support Issues in Disaster Operations
}

\author{
Vedat Shaqiri \\ University of Hertfordshire, Hatfield AL10 9AB, UK \\ vedatshaqiri@gmail.com;
}

\begin{abstract}
The purpose of this research is to identify issues related to logistics support in disaster operations. This was established based on the existing academic literature as well as through the case study of South-East Asia Tsunami event of 2004. Asian tsunami of 2004 pushed academics from logistics as well as practitioners of different subjects to increase their interest in disasters logistics. Despite a plethora of studies in the field of disasters, however, negligible attention has been devoted to the study of logistics issues related disaster relief operations. This study finds that a need for a more in depth examination of logistics issues during disasters operations is a crucial factor in order to improve the response effectiveness in disasters operations. Literature research also reveals that logistics compounds most of the activities of disaster relief operations. The need for further improvements in logistics response concerning disasters is related to the need of disaster logistics to learn and adopt business as well as military logistics practices. Among other issues identified during this research with regards to logistics in disasters include lack of logistics recognition, lack of trained personnel, absence or limited cooperation among acting agencies, inadequate assessment, planning issues as well as other problems as will be discussed. This writing ends with conclusions and recommendations for a more efficient and responsive disaster logistics.
\end{abstract}

Keywords: logistics, logistics support issues, operations, disaster logistics, management, disaster operations, Asian Tsunami. 


\section{Introduction}

The basis for writing this paper with its determined subject is the identification of logistics support issues that countries around the planet are facing during emergency situations. Today the world we live in is comprised from various hazards, known and unknown. During emergency situations the logistics response becomes exponentially complex, due to numerous elements. Disasters, like never before are causing unfavorable consequences to the affected community and to the environment in general. Logistics issues during the time of disasters response have proven to have a direct impact on human life and property. The absence of a continues proper research regarding logistics issues for such circumstances has allowed such actions, derived from human or from nature cause harm to a huge number of people, as well as have tremendous material consequences.

Effective logistics response to disasters is a very complex task to achieve. Each disaster behaves differently and comes with its unique - specific vulnerabilities and hazards. The scale of a disaster determines the logistics capacities needed to involve in support of the affected community.

Disaster logistics is increasingly gaining attention from governmental institutions as well as nongovernmental organizations.

Despite all deficiencies, disaster management, in particular the logistics aspects are improving steadily.

For this paper, scientific material with reference to disaster occurrences have been consulted in order to properly investigate the issues related to logistics in disaster operations.

Events like South-East Asia Tsunami of 2004 have been treated and analyzed from the logistical aspect. Issues related to logistics support during South-East Asia Tsunami of 2004 have served to identify the key elements which led to logistics support deficiencies for the aforementioned large scale disaster.

Other than disasters triggered by natural factors, ongoing conflicts in Afghanistan, Iraq, and Syria are just some other examples where conflicts comprise an important part of the humanitarian relief missions. Conflict zones increase even more the logistics response complexity of humanitarian relief missions.

Literature reveals that nowadays most of the natural disasters and emergency situations affect developing countries. The low economic standard, environmental deterioration are among the main factors which various sources have emphasized play a significant role in making those countries be more vulnerable in facing such emergency situations. 


\section{Methodology}

This research uses the qualitative methodology. One case study serves as a basis of this research. Academic literature recognizes the case study approach as one of the most appropriate methods for logistics research. From numerous researchers, Häkkinen and Hilmola [1] have mentioned that one of the most discussed methodologies regarding logistics research is the approach through case studies, which according to them has the potential to involve qualitative and quantitative methods. Also other authors, Spens and Kovaćs [2] state that after the introduction which Ellram [3] made for Yin [4] regarding logistics management, case studies have been examined closely - scrutinized.

In order to research logistics issues, disastrous events of large scale impact have been considered. Among many disastrous that have occurred in the $21^{\text {st }}$ century, two of them have captured the attention of the world: Earthquake and Tsunami of year 2004 in Asia region as well as Hurricane Katrina in US, just about a year after the disaster in South East Asia.

Both of these disastrous events have drawn the attention of the entire world, very quickly after they hit these particular areas. Considerable help was provided to those in need, which were not little in number.

Fritz Institute alongside with Klynveld Peat Marwick Goerdeler (KPMG) and Massachusetts Institute of Technology (MIT) in order to identify and better understand the situation of humanitarian relief logistics, they altogether with the lead of Fritz Institute initiated a research of humanitarian logistics with reference to the South East Asia Tsunami event, 2004. These three organizations developed a survey and distributed it to 39 international humanitarian organizations, among which 18 organizations voluntarily took part - responded to the survey, with a response rate of $46 \%$.

This paper is also a reflection of scientific articles, personal observation as well as examination of documentary evidence which have served as a complementary research method.

\section{Disater overview}

Disasters have many causes; therefore the response to them is even more complex. After disaster occurrences all potential elements available to respond have always attempted to decrease the consequences of a particular disaster.

\subsection{Disaster definition}

Throughout the history there have circulated various types of explanations regarding disaster definition. The formulation of different definitions depended on distinctive characteristics of a disaster, such as the scale of the event, the hazards, the cause and other elements which constitute a disaster. Depend less of the misunderstandings that scholars might have had in terms of finding a precise definition for disaster events, 
one thing is clear that disasters have happened throughout the entire ages, having a great impact on the affected community.

Various theorists according to Coppola [5] have suggested that many civilizations including the Old Egyptians Empire, the Norse, the Mayans, and the Minoans were not brought to their knees from a particular enemy, but by the effects of disasters events, including floods, earthquakes, famines, tsunamis, El Niño or other large-scale disaster events. Most of the risks that humanity faces today have been present for the prehistoric ancestors too. Archeological studies have discovered that risks such as dangerous wildlife, violence triggered by humans, starvation, diseases and other risks have been part of the prehistoric ancestors as well. Authors, such as Coppola [5] emphasize that these inhabitants took measures to reduce or mitigate their risks; they did not just sit and wait for the problems to disappear on their own pace of activity. The countermeasures taken by those people demonstrate management to disaster events. According to the Oxford Dictionary [6] the term "Disaster" has its origin from the 16th century of an Italian word „dis " which basically has the meaning of a negation expression and from the second part "astro" which has the meaning of a star. From the two-combined words it is understood that the term disaster generally means ill starred event, as explained from the Oxford Dictionary.

With reference to Oliver-Smith and Hoffman [7] disasters are periods in which people experience a so called vast spectrum of intense emotions - loss, anxiety, terror, fear, grief, anger, relief, gratitude, frustration and resignation, in all their shadings and intensities.

According to the World Health Organization (WHO) [8] a disaster is "an occurrence disrupting the normal conditions of existence and causing a level of suffering that exceeds the capacity of adjustment of the affected community."

Many definitions come across in the literature regarding disaster term definition, it all depends from which corner different groups of societies or organizations observe it. Similarly, other authors, including Flin [9] state that there is no widely agreed meaning for the term disaster. Before all, no matter if people disagree on how the final definition of the term disaster should look like, one thing that we all have to agree on are the serious problems which come from those events for which we always have to come together and be prepared.

\subsection{Disaster types}

During the whole modern history disasters have been classified in different categories. Disasters types as well as its definitions have been subject of discussions to many researchers. Authors Turner and Pidgeon [10] have discussed in detail the definition regarding the types and the definition of disasters. The American Federal Emergency Management Agency (FEMA) [11] is among the institutions which have played a significant role in recent years, concerning definitions, types and the scope of disaster management.

Numerous research institutions from various fields dealing with disaster management have reviewed and have mainly divided disasters in two major categories. Natural and Man-made disasters are the two most mentioned categories of disasters found in to- 
day"s literature. There is also a third type of disaster, referenced as Hybrid Disaster, also found in different academic sources. It is believed that the three aforementioned types of disasters cover all possible disastrous events.

\section{$4 \quad$ Defining Logistics}

Regarding logistics definition, there exist a number of widely accepted definitions. Among many authors, Rutner and Langley [12] have highlighted the "Seven R"s" definition brought by Shapiro and Heskett. The Seven R"s describe logistics in a form that it should be able to ensure the availability of the right product, in the right quantity, in the right condition, at the right place, at the right time, for the right customer and for the right cost.

Logistics originated from the military planning process. Military needs dictated the creation of such a department within the military units, in order to fulfill the requirements of the soldiers in the field (terrain), as well in the daily base operation.

Kumar and Chia [13] highlight that logistics purely was firstly introduced by the military, and was also further developed by military operations. Nowadays it has been broadly embraced in the non-military world. Business management has widely adopted logistics for its beneficial effects in the field of production, manufacturing industries, and other related business fields.

Logistics from business perspective is defined as: a business planning framework for the management of material, service, information and capital flows. It includes increasingly complex information, communication and control systems required in today"s business environment [14].

\section{$5 \quad$ Similarities between disaster logistics and business logistics}

Business or commercial logistics has a broader scope in terms of literature as well as in practice. Different from disaster logistics, business logistics has a long history of experiences which undoubtedly all this background has enabled this particular field to grow in quantity as well as in quality. Business logistics with all its accompanying components has improved its capacity and continually has contributed to a better performance of businesses in the commercial sector.

On the other hand disaster logistics even though not as experienced as business logistics it is developing itself steadily. Logistics experiences as well as findings from literature reveal that there are various opportunities in different areas where disaster logistics can constantly improve its capabilities.

The similarities between disaster and business logistics offer favorable circumstances for an increased effort for coordination and collaboration between them.

Disaster logistics advancements can be further developed by implementing strategies which have had a good result in previous logistics operations of other fields than in emergency operations.

Researchers are not on the same line whether commercial practices can serve logistics of disasters as a guide towards improving logistics operations in disasters events. 
Among others Menzies III and Helferich [15] have suggested that humanitarian logistics cannot advance by adopting best commercial practices due to the differences these to fields have between them. Other authors including Kovács and Spens [16] have emphasized that there are considerable characteristics which set apart disaster logistics from business logistics.

Business as well as disaster logisticians operate in complex networks which require proper risk assessments. Even though commercial logistics is more easygoing in managing responses, they still have similarities with disaster logistics concerning the management of rapid responses and other demands driven by further circumstances. Coordination and Collaboration as well as the sharing of information are elements that both logistics parties rely on in order to enhance their response to specific demands.

Another similarity that has been noticed when comparing logistics engagement is that both disaster and commercial logistics establish procedures that they follow in providing solutions to certain situations related to their jobs.

Similarities are visible also in terms of how they want to save money. Both parties attempt to meet the needs with a minimum amount of budget.

According to Bealt, Fernández Barrera and Mansouri [17] even though humanitarian logistics definition has similarities with commercial logistical definition, they are different in some key aspects. Among many key differences Holguin-Veras et al., [18] highlight that business sectors attempt to minimize cost, whereas humanitarian organizations aim to lower the level of human suffering.

On the other hand Beamon and Balcik [19] mention that from the supply chain perspective, partnerships between humanitarian and business logistics are feasible due to the fact that most elements of supply chains are similar in both sectors. Therefore they emphasize that tools and methods which are developed for business supply chains can be suitable to humanitarian relief operations.

\section{Identified logistics issues}

As emphasized earlier, the survey was developed by Fritz Institute with further help by Klynveld Peat Marwick Goerdeler (KPMG) and Massachusetts Institute of Technology (MIT). Then it was distributed to 39 international humanitarian organizations, among which 18 organizations voluntarily took part as well as responded to the survey, with a response rate of $46 \%$. In total 100 participants responded to the survey, since there were few members that worked on same organizations. The survey was compound from ten elements - parts through which issues related to this disaster were attempted to be identified. Those elements included:

1. Preparedness

2. Assessment and Appeal

3. Resource Mobilization

4. Procurement

5. Transportation Execution

6. Track and Trace

7. Stock Asset Management 


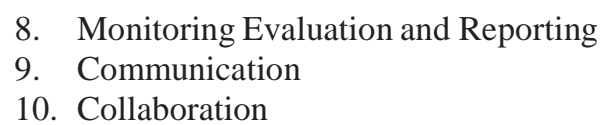

\subsection{Preparedness}

About $72 \%$ of the engaged organizations during this operation have declared that they had plans considering relief operations. After they experienced the disaster only $38 \%$ of the intervening operations stressed that the established plan during this phase fulfilled their needs. The results of this survey emphasize that among all organizations $50 \%$ declared to have had inaccurate plans after having put their plans in action.

Undoubtedly the uniqueness of this disaster has caused organizations not to have the usual effectiveness of their planning considerations. Fritz Institute through this survey has noticed that only $33 \%$ of the interviewed respondents have confirmed to have distributed their actions plan according to guidelines established earlier. Therefore this lack of communication can be another element with possible impacts for the preparation phase. The absence of a well - organized plan of an organization hinders its strength to efficiently move to other steps of this long process, directly followed by assessment and appeal as well as mobilization of resources

\subsection{Assessment and appeal}

At first organizations had no accurate assessments regarding the beneficiaries, locations and other related logistics elements. This caused logistics issues due to the lack of information. Logistics organizations did not have accurate information from the ground - tsunami affected population.

It has been mentioned that this lack of information was as result of various factors, but surveyed organizations have mostly emphasized two aspects:

1. Lack of trained staff from local communities.

2. Infrastructure destruction has limited logistics organizations to have a full access to the impacted regions.

Organizations that were having information gathering problems were not able to use information from other organization which possibly had more resources on ground at this particular point.

The surveyed organizations, mentioned that $76 \%$ of them conducted independent assessments and only $38 \%$ administered independent and joint assessments. It has also been reported that another issue during assessments was the lack of knowledge of the assessing staff. Among all the members of different teams about $88 \%$ of members that conducted assessments came from abroad - international. On the other hand 38\% of the intervening organizations had members who conducted assessments and were from local communities with specific knowledge for their neighborhood.

Another important logistics assessment issue was the absence of logisticians in assessment teams. The survey revealed that although most of the humanitarian organizations had created multi-disciplinary assessment teams, but only $58 \%$ of those teams 
had a logistician in their assessment structure. Absence of local members as well as professional logisticians made it even harder the collection of proper information.

Information accuracy has been mentioned to have been the most acute element especially in Indonesia because of historical lack of organizational as well as trained staff members. Roads were completely destructed which consequently caused problems in the assessment process. Based on the information provided from the conducted survey, infrastructure damage in Sri Lanka was less severe compared to the complete destruction of roads in Indonesia.

\subsection{Resource Mobilization}

Fritz Institute designed the survey to assess resource mobilization in a format that it analyzed three different categories: Human Resources, Financial Resources and Organizational Set Up.

\section{Financial resources}

As previously emphasized the response to this highly destructive magnitude of this tsunami was unprecedented from worldwide organizations and people. There has been received only one response from the survey where it was stated that financial resources were not on hand when they were necessary.

\section{Human resources}

The survey analyzed the engaged human resources in particular logistics operations during the tsunami relief. This part of the survey examined the quality, quantity as well as the training level of the teams at regional, national, international and area level. Evidences show that members of many organizations were not capable of doing their job due to the fact that they had no specialized logistics training in advance. This was mainly noticed at "local area level" of intervention, whereas on the other hand international staff has been rated to have been more experienced related to specific expertise as well as properly trained personnel. Despite the expertise from the international organizations, they still were not able to mitigate the deficiency of trained personnel at local areas. This survey has revealed that $88 \%$ of members of different organizations had to retrieve their assigned personnel from other ongoing operations, and then this percentage was fulfilled with headquarter personnel who were sent to field operations. All this was done in order to mitigate the lack of trained personnel for such disaster support operations. Timeliness of having people ready to deploy to the impacted area has also been subject of this survey analysis. It has been reported that $50 \%$ of organizations had stand by mechanisms ready to deploy, whereas $72 \%$ of surveyed organizations used roster lists. Organizations, due to funding issues could not hire long-term staff. Therefore most of contracts have been set from one to three months, and there were a few contracts lasting from three to six months. 


\section{Organizational setup}

Intervening organizations utilized a hub for interagency coordination. $72 \%$ of all engaged organizations participated in utilizing this coordination among various responding organizations. Later, most of organizations did establish their own sites in different local areas.

\subsection{Procurement}

All relief organizations have executed procurement processes during the disaster response, which had been established in advance. Despite the steps taken to arrange a well organizes procuring process, over $50 \%$ of the organizations have faced procuring delays. These delays were mainly caused due to simultaneously requests of organizations which were asking for same items - products. This undoubtedly resulted in shortages as well as in procuring delays. The results of the survey have revealed that approximately $50 \%$ of organizations which had pre-established agreements were dedicated for medical supplies, $56 \%$ for non-food products and $70 \%$ for vehicle equipments. The higher percentage of vehicles been ordered indicates the importance of them in disasters reliefs efforts. Respondents of various organizations have indicated that only few of them had established in advance agreements for food items, because of the sensitivity food supply sources have related to location as well as timing.

Among many donations there have been reported some unsolicited donations as well. From all unsolicited donations, unsolicited vehicle donations were reported to have had a great positive impact improving logistics support operations during the Tsunami event 2004 in South -East Asia. Vehicles were the only items to have had value among all other unsolicited items. From the survey it has been understood that if organizations had established processes which would stop unsolicited goods before they reached local areas, the effects of unsolicited items would have been negligible.

Nevertheless, if unsolicited reached impacted communities, negative effects to relief chains are unavoidable. This is due to the time and effort consumed needed to identify the unsolicited donation, prioritize products and then store them or transport them to a adequate place. All these elements waste valuable resources.

\subsection{Transportation}

Physical infrastructure was largely affected by the tsunami event. Organizations which were engaged in relief operations, mentioned that roads and airfields were destructed at that level which directly impacted transportation execution. They have also emphasized that customs have also caused extra delays in responding to affected areas. Most of the respondents, about $94 \%$ have highlighted that they experienced transportation issues, because of the poor infrastructure.

The Tsunami effects related to infrastructure could be noticed just by observing destroyed coastal roads in Sri Lanka and Indonesia. Transportation of many supply items to many locations could be delivered only by helicopters. Among all organizations, $76 \%$ of the respondents taking part in this survey have declared to have used air transportation to reach particular areas. As mentioned above, customs have caused delays, and for this particular issue $71 \%$ of respondents have emphasized to have had 
this bottleneck in their work, in particular logistics organizations in Indonesia and Sri Lanka. With significance Indonesia was changing its customs procedures constantly, which made logistics flow very slow. Due to internal problems with rebel groups, the government of Indonesia was controlling sensitive equipments including radio equipments and medical supplies more heavily in order to make sure they were not used for wrong reasons by rebel groups.

\subsection{Track and Trace}

Literature has revealed that during disaster relief operations, organizations providing logistics aid to affected communities have had problems in tracking and tracing their supplies. This survey from Fritz Institute has validated these aforementioned observations by other researchers. During the tsunami relief humanitarian organizations have used solutions which were on ad-hoc basis. Among all respondents, 26\% have declared to have used special software for tracking \& tracing for their procured products. On the other hand those that were not able to use particular software had no other choice than to use Excel Spreadsheet or do it in a manual manner.

Despite the lack of proper tracking and tracing software $58 \%$ of all organizations have responded to have received accurate and timely updates regarding the status of their products. Fritz Institute doubted this accuracy by further challenging its research through some other interviews, which at the end this institute justified its skepticism

\subsection{Stock asset management}

Most of the organizations have responded to have had inventory management systems as well as well as procedures. Among all respondents $85 \%$ have highlighted that these management systems met their needed requirements for their logistics relief operations. Fritz Institute through this survey has revealed that after the struck of Tsunami 2004 not all inventories were put in place. After this occurrence there have been tentative to pre-position stocks strategically.

\subsection{Monitoring, Evaluating and Reporting}

Another reported issue related to logistics operations during disasters operations is reporting. All engaged organizations do report to their particular headquarters as well as donors. During the tsunami event relief, donor reports were done by finance organizations, and had not logistics teams involved. Over $73 \%$ of organizations have stated that they evaluate (measure) their chains of supply, from the time of placed order, to the time of delivery. Fritz Institute suggests that a broader measurement is required to monitor as well as improve the effectiveness of supply chains. Effectiveness of the chains of supply shall be directly linked to the goals and objectives of the organization 


\subsection{Communication}

Satellite and cellular phones were used at about $83 \%$ of organizations for communication reasons during the first week of the operations. After a week $50 \%$ of organizations used e-mail as a source of communication. Respondents have declared to have experienced communication issues during the tsunami relief operations. According to the surveyed organizations, $81 \%$ of them have reported to have faced communication problems.

\subsection{Collaboration and Coordination}

As mentioned earlier, intervening organizations have always had issues to collaborate with each other. The aspect of collaboration is a very important factor in relief efforts, but it has been emphasized to be challenging in accomplishing it. Survey results show the below listed information:

- $\quad 77 \%$ of all organizations coordinated activities with local authorities

- $69 \%$ worked with military units

- $77 \%$ worked with private businesses

- $56 \%$ collaborated with agencies to set up their chains of supply

The above results from the survey show a positive attitude of collaboration among different agencies. However, Fritz Institute stresses that this collaboration was realized on ad-hoc basis. Immediate needs of particular organizations resulted in interagency collaboration and coordination.

\subsection{Concluding remarks}

Except the aforementioned issues, respondents at the end of the survey emphasized some other bottlenecks which they thought had played a negative impact in the logistics operations during the South-East Asia 2004 tsunami disaster. Among many composed final thoughts Fritz Institute has underlined the following:

- Logistics coordination should be organized by a central group and NGOs shall do the implementation

- Better coordination was established when meetings were conducted at the beginning of activities

- In Sri Lanka many government agencies involved their selves in particular subject, making it even more complex to conduct logistics relief operations

- Not enough space with fresh air for too many people in various environments

- Airport was overloaded

NGOs competed for very limited resources, because everyone was looking for almost same logistics items. 


\section{Conclusion and Recommendations}

Tsunami event of 2004 which occurred in South-East Asia served as a reference point to investigate the most predominant issues related to relief efforts, with emphasis on logistics support issues during these disaster relief operations. Except the Tsunami event of 2004 in South-East Asia, a number of scientific articles were consulted in order to be able and compare the findings from the survey of Fritz Institute and those found in other literature resources.

This research has revealed that Boxing Day Tsunami 2004 was a turning point in gaining the attention of logistics importance during disasters response. Many organizations, including governmental and nongovernmental agencies after this event have realized that logistics is crucial and plays a significant role during the disaster relief operations.

The discussed literature along with the analysis of Tsunami 2004 shows that logisticians need to improve certain processes in their work. This will not affect only aid delivery efficiency but will also increase logistics recognition. Lack of trained personnel was identified as one of the major issues related to logistics operations during disaster relief efforts. Even though this paper treated the Tsunami 2004 operation in South-East Asia, this is found to be a common issue in today"s disaster logistics support operations. Through the survey of Fritz Institute it was clear that issues which different humanitarian organization face in disasters response are mostly common for all types of organizations, depend less of their size.

It is evident that local staff plays a significant role in disasters response. The lack of trained local staff during the tsunami event of 2004 in South-East Asia as well as other cases reveal that this constitutes an issue of a proper assessment and logistics response in general. Lack of trained personnel, means lack of expertise in the organization, which results negatively to the organization in implementing standardized approaches. The absence of implementing prior-defined procedures leads to ad hoc solutions for which researchers have concluded that reduce the response effectiveness to disaster events.

Another issue identified is related to supply chain. From the researched literature we can highlight that supply chain processes exist in disaster response, but organizations do not use advanced methodologies in monitoring and evaluating their chains of supplies for future improvements. It was also found that aid agencies do not pay attention in establishing well developed logistics reports, because they think they are unworthy and time consuming.

Assessment has been recognized to be among most essential problems during the initial phase of response. From the observed cases of logistics response it was noted that organization at the very first phases after the disaster occurrence depend on local personnel to do the initial disaster assessment and the related logistics need to respond. Specifically from the South-East Asia Tsunami 2004 experience, many organizations had no personnel in the affected area, and the local staff had no knowledge how to do a well organized assessment. This was a huge issue due to the fact that relief organizations had no information of what logistics resources were needed.

Despite all issues concerning coordination and collaboration, it is found that during the Boxing Day Tsunami event 2004, maps, certain websites and logistics publications were significant in providing logistics coordination during relief operations. 
As a conclusion we can emphasize the need for a better planning of all disaster response phases. A well established plan in "peace" will result in fewer issues in real "battle", and this at the end will result in less victims and injured people.

It is highly recommended for governmental organizations establish realistic plans for possible response to disaster occurrences. For them is very important to have such logistics plans in place due to the fact that they will be the main responsible element during the response phase.

From personal observation developing countries have a tendency of ignoring the creation of plans to react to disaster events. Except that, they are not proactive, they neglect their capacities and just wait for other international organizations to come and help. This personal observation becomes even stronger taking into consideration the fact that most of governments of developing countries allocate very modest efforts in equipment and training purposes. There is also a need to develop study programs associated to disaster management. This field of study is not popular in developing countries, but is with huge interest for the benefit of particular countries.

It can also be concluded that there is an immediate need to advance the cooperation with the commercial sector in establishing among others track and trace software for supply chain activities. Also, there is a need for a further investigation in determining the pre-positioning issue, emphasized during the response to South-East Asia Tsunami event. In addition logistics relief operations need more attention to advance and eliminate issues related to assessment, cooperation \& collaboration and human resources as outlined from Fritz Institute survey. Researchers have to intensify their efforts in finding opportunities to adopt practices from logistics commercial world in improving the aforementioned fields.

Finally, having in mind that Thomas and Kopczak [20] have warned us that natural and man-made disasters will increase five-fold in the next 50 years, it is crucial for all of us to contribute as much as we can in improving logistics practices in order to make the next disaster response better than the last. 


\section{References}

1. Hakkinen L, Hilmola O (2005) Methodological pluralism in case study research: an analysis of contemporary operations management and logistics research. International Journal of Services and Operations Management 1:239. doi: 10.1504/ijsom.2005.006576

2. Spens K, Kovacs G (2012) Mixed methods in logistics research: the use of case studies and content analysis. International Journal of Physical Distribution \& Logistics Management. doi: 10.1108/ijpdlm.2012.00542caa.001

3. M. Ellram L (1996) Ellram, L. (1996). The use of the case study method in logistics research. Journal of Business Logistics Vol. 17(2):93-137.

4. Yin R (1984) Case study research: Design and Methods. CA: Sage Publications

5. Coppola D (2011) Introduction to international disaster management. Amsterdam: Butterworth-Heinemann/Elsevier

6. (2018) disaster | Definition of disaster in English by Oxford Dictionaries. In: Oxford Dictionaries | English. https://en.oxforddictionaries.com/definition/disaster. Accessed 10 Oct 2018

7. Oliver-Smith A, Hoffman S (2012) The Angry Earth. Taylor and Francis, London

8. (2018) WHO | South Asia earthquake and tsunamis. In: Who.int. http://www.who.int/hac/crises/international/asia_tsunami/en/. Accessed 10 Oct 2018

9. Flin R (1998) Safety Condition Monitoring: Lessons from Man-Made Disasters. Journal of Contingencies and Crisis Management 6:88-92. doi: 10.1111/1468-5973.00076

10. Turner B, Pidgeon N (1997) Man-made disasters. Butterworth Heinemann, Oxford

11. (2018)In: Training.fema.gov. https://training.fema.gov/emiweb/downloads/is10_unit3.doc. Accessed 3 Oct 2018

12. Rutner S, Langley C (2000) Logistics Value: Definition, Process and Measurement. The International Journal of Logistics Management 11:73-82. doi: $10.1108 / 09574090010806173$

13. Kumar S, Chia A Commercial Logistics vs. Military Logistics. Cases on Supply Chain and Distribution Management 290-329.

14. (1996)Logistix Partners Oy, Helsinki, FI

15. Menzies III J, Helferich O (2013) Humanitarian Relief and Broken Supply Chains.Advancing Logistics Performance. TR News National Academy

16. Kovács G, Spens K (2007) Humanitarian logistics in disaster relief operations. International Journal of Physical Distribution \& Logistics Management 37:99-114. doi: $10.1108 / 09600030710734820$

17. Bealt J, Fernández Barrera J, Mansouri S (2016) Collaborative relationships between logistics service providers and humanitarian organizations during disaster relief operations. 
Journal of Humanitarian Logistics and Supply Chain Management 6:118-144. doi: 10.1108/jhlscm-02-2015-0008

18. Holguín-Veras J, Pérez N, Jaller M et al. (2013) On the appropriate objective function for post-disaster humanitarian logistics models. Journal of Operations Management 262-280.

19. Beamon B, Balcik B (2008) Performance measurement in humanitarian relief chains. International Journal of Public Sector Management 21:4-25. doi: $10.1108 / 09513550810846087$

20. Thomas A, Kopczak L (2005) From logistics to supply chain management. The path forward in the humanitarian sector. Frittz Institute 